\title{
Article \\ Using Game Design to Teach Informatics and Society Topics in Secondary Schools
}

\author{
Fares Kayali 1 ${ }^{1,}$, Vera Schwarz ${ }^{2}$, Peter Purgathofer ${ }^{1}$ and Gerit Götzenbrucker ${ }^{2}$ \\ 1 TU Wien, Human Computer Interaction Group; \{fares,purg\}@igw.tuwien.ac.at \\ 2 University of Vienna, Department of Communication; \{vera.schwarz, gerit.goetzenbrucker\}@univie.ac.at \\ * Correspondence: fares@igw.tuwien.ac.at; Tel.: +436769421442
}

\begin{abstract}
:
This article discusses the use of game design as a method for interdisciplinary project-based teaching in secondary school education to convey informatics and society topics. There is a lot of knowledge about learning games but little background on project-based teaching using game design as a method. We present the results of an analysis of student-created games and an evaluation of a student-authored database on learning contents found in commercial off-the-shelf games. We further contextualise these findings using a group discussion with teachers. Results underline the effectiveness of project-based teaching to raise awareness for informatics and society topics. We further outline informatics and society topics that are particularly interesting to students, genre preferences and potentially engaging game mechanics stemming from our analyses.
\end{abstract}

Keywords: game-based learning; game design; project-based teaching; informatics and society, cybersecurity

\section{Introduction}

This article discusses the use of game design as a method for interdisciplinary project-based teaching in secondary school education. Secondary school education has to handle a lot of learning contents that are defined in the curricula, resulting in considerable pressure to accommodate them. Thus incorporating specialised and interdisciplinary subjects into regular teaching is a challenge. For this reason our contribution is valuable as it outlines a specific case of interdisciplinary project-based teaching. Over a period of one year secondary school students created analogue and digital games in computer science and arts classes. The games incorporate topics from informatics and society such as copyright, privacy, cyber bullying, technical literacy and social media use. This article will describe how project-based teaching can work in such a setting, which contents students choose, which game elements appeal to them and what kinds of learning experiences they had.

There are several examples of existing learning games, which deal with topics from informatics and society. [1] give an overview of studies on Internet learning games. Internet Hero follows several of J.P. Gee's learning principles [2] in presenting topics around the Internet for children aged 8 to 12 [3]. [4] discuss the potential of learning games for teaching cyber security, including topics like malware, email and spam.

Cyberworld Adventure [5] and Net-Detectives [6] are games, which teach safe Internet use to 9to-12 year-old children. Anti-Phishing Phil [7] is an online game, which explains how to protect yourself from phishing attacks. All three studies show positive impact on children's knowledge about the Internet. SimSafety [8] also deals with Internet security. The results of an earlier study on the game are documented in [9]. CyberCIEGE [10] is a resource management simulation that lets students understand the impact of security choices on an organisation. All of these references are examples of successfully translating topics from informatics and society into a game-based form, but there are little insights into how they can be integrated into school teaching and how to design game-based 
contents in a way that appeals to school students. With regard to genre, [11] looked at learning effects by game types. They saw an increase in learning effects with action games compared to other genres such as puzzle games. But this result has limitations as the action game tested followed a behaviourist approach compared to the constructivist nature of the other games tested.

In an analysis of 21 cybersecurity games, three different types of games were identified by the authors; "those whose gameplay is not associated with cybersecurity education content (Type 1); those that integrate multiple-choice decisions only (Type 2); and those that integrate cybersecurity objectives into authentic gameplay activity (Type 3)." [12]

[13] designed and deployed a board game for cybersecurity education. The main challenges they identify are; relevance of the game to the curriculum, appropriateness for and accessibility to the target audience, and how to best evaluate the impact of such a game. Control-Alt-Hack [14] is a card game about cybersecurity. A study with 14 teachers of 450 students indicates that the game helped raise awareness and changed the perception of cybersecurity topics of students. Likewise, SecurityEmpire [15], a digital game to promote cybersecurity education, showed the ability to raise awareness for issues around cybersecurity.

In our project students created both board games and digital games. We follow the core research question: "How can game- and game design-based learning be used to teach topics from informatics \& society and to increase game literacy of secondary school students?". This further leads to subquestions such as "Which learning contents do secondary school students choose on their own?", "Which kinds of games do they create to communicate these contents?", and "How much can this kind of project-based teaching contribute to learning experiences regarding informatics \& society and game literacy."

The educational project Sparkling Games [16] formed the basis for our analysis. It starts with a detailed analysis of existing learning and mainstream commercial games. Students then step by step conceptualise and develop games to support teaching areas including copyright and intellectual property, privacy, surveillance, social media, and big data. The project is meant to transfer academic skills to students, who gain expertise in the areas of game design and serious games as well as in social science research methods intended to assess and reflect on their creations. Key results of the project include a commented collection of existing games supporting learning about informatics and society, new games and game concepts developed by students, and bottom-up insights into how game-based learning can be used in schools. Sparkling Games strives to expand the potential of games as media for learning, reflection and for teaching media literacy. The presented paper will focus on the first step of the project where students identified examples of games with learning contents and on the games created by students later in the project. We will present the results of a thematic analysis of the entries made by students into an online database and of the games they created, along with a critical reflection of the project's impact by the involved teachers.

We take a secondary school student-centered perspective on game- and game design-based learning in the area of informatics \& society. From this perspective we present the following core results:

- a collection of learning contents and ways of delivery identified by students in commercial games

- a collection of analogue and digital games created by students, and an analysis of which topics they chose and how these topics are communicated

- insights into how project-based work with games and game design can raise awareness for topics from informatics \& society

- insights if project-based work with games and game design can increase game literacy

\section{Materials and Methods}

\subsection{Project Context}

Together with secondary school students the project Sparkling Games investigates how concepts from the field of game-based learning can be used to develop learning methods and teaching 
materials. These methods and materials are supposed to enable the integration of the topic "informatics and society" into computer science classes as well as into other subjects, e.g. arts. The choice of topics follows the computer science curriculum and the official guidelines for media education issued by the Austrian ministry of education. Coverage of topics revolving around informatics and society in schools is explicitly intended in the respective curricula. In the syllabus of the 9th grade the following specific wording is found: "The students are supposed to learn about essential measures and legal basics concerning data security, privacy and copyright as well as to understand the effects of the use of technology on individuals and the society." [17]

In fact the social context is often severely disregarded in schools and the instruction mainly focuses on technical skills and competencies. In the light of constant social change it is becoming more and more important to deal with sociopolitical issues in classrooms in a systematical and structured way. In recent years the spread of technical development has increased considerably. Hence new areas of tension arise in society that are of major importance for everyday life. Questions concerning copyright and intellectual property, privacy and surveillance, social media and big data, digital vulnerability and dependency of users have quickly evolved from side issues into central issues of sociopolitical debates. Consequently, the consideration of relevant topics in class is becoming more and more important. The project Sparkling Games addresses these issues that are difficult to integrate into instruction.

The project goal is the design of learning games in the area of informatics and society by the participating secondary school students. The range of created games may comprise board and card games as well as computer and console games. The participating scientists support the students, observe the process and evaluate the results. Thus, conclusions about successful and geared-to-thetarget-group design of learning games can be drawn. Furthermore, the project team analyses if and how well the chosen approach of designing learning games is suited as a teaching method. The target audience of the created games are students in grades 9 to 13. An exhibition of the games at the game trade show GameCity in Vienna's town hall is the project's conclusion and highlight. A discussion of the project results between the participating and other interested teachers was conducted in this setting.

The project Sparkling Games encourages an exchange of ideas and skills between the participating secondary school students and scientists. Expertise in the areas of game design and reflection on as well as evaluation of games is imparted to the students. Also, valuable insights on designing learning games can be gained. In contrast to conventional research approaches these insights are not formed by rating existing products-instead they arise directly from the target audience.

\subsection{Sample}

We worked with three different secondary schools in Vienna, Austria; one grammar school (gymnasium), one trade school and a technical school. There were large differences in the learning environments of the schools participating in the trials (in terms of the technology available and the knowledge of the student base), which presented significant challenges. However, through game design workshops, presentations and discussions, it was possible to partially offset these differences. There were four teacher involved with the project. Overall there were around 70 students (the number fluctuated due to drop-ins and -outs over the school year) who participated in the project in groups of two to five students. 55 entries were made into the game database, and a total of 18 games (11 board games and 7 digital games) were created over the course of the project.

\subsection{Methods}

The database entries were evaluated using thematic analysis [18]. Three researchers independently identified categories that were later discussed and merged. The creation of games by students was based on Høbye \& Löwgren's "research-through-explorative-design" approach [19]. This approach is shaped by three essential components, which also refer to works by [20] and [21]: "(1) a focus on "sketching with technology", [...] is used to explore issues of behavior and enactment 
(as opposed to envisionment) [...], (2) experimentation in the sense of making and trying out prototypes or partial prototypes is the primary mode of working [...], and (3) the goal of the experiments is to grow an understanding and a sensibility for the experiential qualities of embodied interaction's materials and ensembles." [19, p. 33]

The games were later played by the research team in a reflective manner akin to Aarseth's concept of playing research [22]. Then two researchers discussed the games and developed a categorisation together. A group discussion was held with four teachers and four researchers of the project team. The group session was audio recorded and a mind map was made and discussed during the session. The session was evaluated using thematic analysis to refine the categories established in the mind map.

\section{Results}

\subsection{Database}

In the presented study high school students were asked to look for examples of the topic informatics and society or other interesting learning content in games (board games as well as video games). They documented the games they came upon in an online database developed specifically for the research project (figure 1). Database entries could refer to whole games covering the respective topic or just segments of common games. Regarding games dealing with more than one topic, we encouraged one database entry per topic. The students were prompted to accurately describe how the selected game addresses the topic/learning content they found appealing and illustrate this utilizing videos and pictures. Also, we requested them to use tags to organize the topics in question.

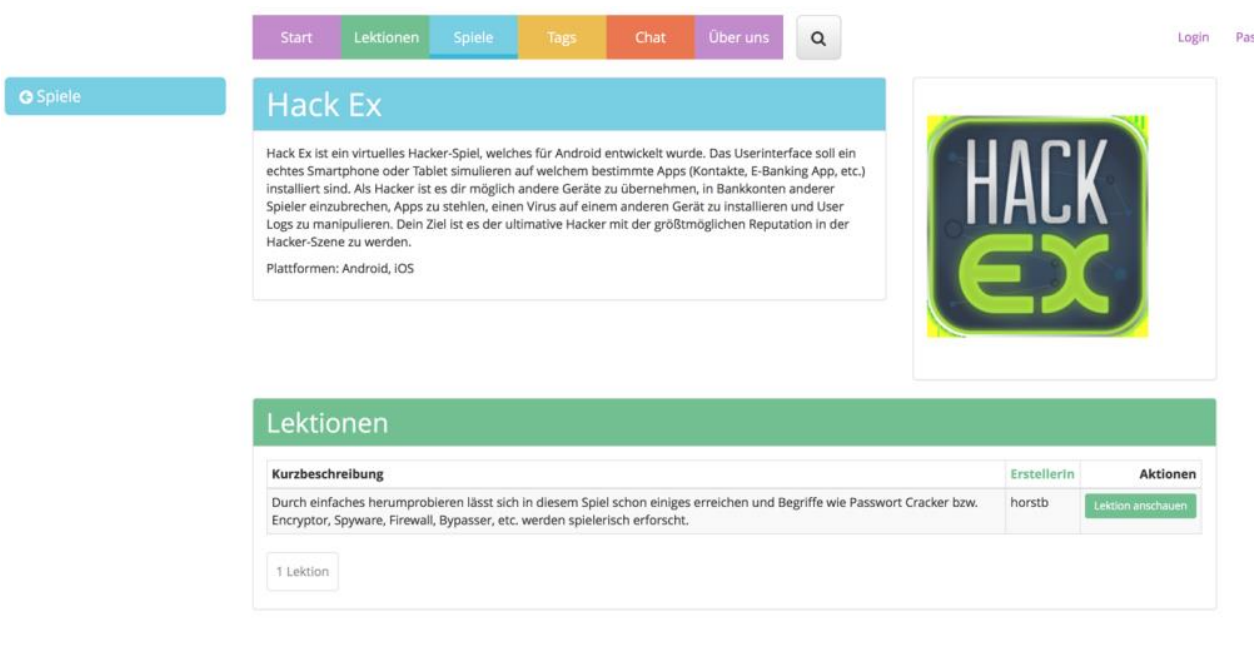

Figure 1. Entry for the game "Hack Ex" in the Sparkling Games database

We conducted a thematic analysis of 55 database entries altogether (see table 1 for an overview). Three researchers independently identified categories that were later discussed and merged. The most frequently recorded game genres are open world and shooter (10 mentions each), simulation, action adventure, jump'n'run (6 mentions each), racing and strategy (5 mentions each). Board and card games, respectively, are hardly mentioned (4 times, in comparison to 51 mentions of digital games). Mobile games (6 mentions) and casual games (4 mentions) are of surprisingly little importance. The topics most often identified in the recorded games are war (15 mentions), society (13 mentions) and morality or moral decisions (13 mentions), followed by fantasy (8), history (7), politics and economy (5 each). Although when given the task, the students were explicitly challenged to find example games for informatics \& society topics, there are only rather few mentions of such. We conclude that the threshold to solving the task was too high, considering the students' relatively low knowledge about game design as well as informatics \& society topics. The mentioned informatics \& 
society topics are hacking (5 mentions), privacy, informatics know-how, artificial intelligence/conscious machines ( 2 mentions each), cybercrime and robotics (1 mention each). Last, we analyzed the mechanics used to convey the topics/learning contents covered above. Here, acting strategically, competition (16 mentions each) and cooperation (15) are most significant; the obvious importance of playing within a social context, either together or against each other, is remarkable. A game's narrative (13 mentions), repetition and taking another's perspective (11 mentions each) are of relevance, too. Other commonly quoted mechanics include a dystopian game setting, systemic learning, learning through trial \& error (8 mentions each), acquiring factual knowledge (7) and exploration (6).

\begin{tabular}{|l|r|}
\hline GENRE & count \\
\hline Open World & 10 \\
\hline Shooter & 10 \\
\hline Simulation & 6 \\
\hline Action adventure & 6 \\
\hline Jump 'n' Run & 6 \\
\hline Mobile & 6 \\
\hline Strategy & 5 \\
\hline Racing & 5 \\
\hline Survival & 4 \\
\hline RPG & 4 \\
\hline Casual & 4 \\
\hline Board-/Card Game & 4 \\
\hline MMORPG & 3 \\
\hline Adventure & 2 \\
\hline MMO & 2 \\
\hline Trading Card Game & 2 \\
\hline Puzzle & 1 \\
\hline Music Game & 1 \\
\hline Beat'em Up & 1 \\
\hline
\end{tabular}

\begin{tabular}{|l|r|}
\hline TOPIC & count \\
\hline War & 15 \\
\hline Society & 13 \\
\hline Moral decisions & 13 \\
\hline Fantasy & 8 \\
\hline History & 7 \\
\hline Hacking & 5 \\
\hline Economy & 5 \\
\hline Politics & 5 \\
\hline Sports & 4 \\
\hline Crime & 3 \\
\hline Videogames & 2 \\
\hline Privacy & 2 \\
\hline Informatics know-How & 2 \\
\hline Artificial intelligence / & 2 \\
\hline Conscious machines & 2 \\
\hline Ressources & 1 \\
\hline Sustainability & 1 \\
\hline Consumerism & 2 \\
\hline Cybercrime & 1 \\
\hline Robotics & 1 \\
\hline Urban planning & \\
\hline Music & \\
\hline Riddles & \\
\hline
\end{tabular}

\begin{tabular}{|l|r|}
\hline MECHANIC & count \\
\hline Acting strategically & 16 \\
\hline Competition & 16 \\
\hline Cooperation & 15 \\
\hline Narrative & 13 \\
\hline Repetition & 11 \\
\hline Taking another's perspective & 11 \\
\hline Trial \& Error & 8 \\
\hline Systemic learning & 8 \\
\hline Dystopia & 8 \\
\hline Acquiring factual knowledge & 7 \\
\hline Exploration & 6 \\
\hline Empathy & 4 \\
\hline Acquiring practical knowledge & 2 \\
\hline Logical reasoning & 1 \\
\hline Satire & 1 \\
\hline Constrained scope of action & 1 \\
\hline Singing & 1 \\
\hline
\end{tabular}

Table 1. Overview of the analysis of genres, topics and mechanics in the Sparkling Games database

\subsection{Games}

Overall the students created 18 games, 11 board games and 7 digital games, one of them a virtual reality game. Board games were started in school and finalised using materials provided during a dedicated board games workshop. The digital games were created as part of a year-long technical school project, using either the Unity or Unreal 3D game engines.

In following we will first describe the genres and game mechanics of the games (see figure 2 for examples) before discussing the embedded informatics and society topics and associated learning mechanics. The genre and mechanics terms for analysing the board games are inspired by the categories used by the vastly popular board game index site BoardGameGeek [23]. 

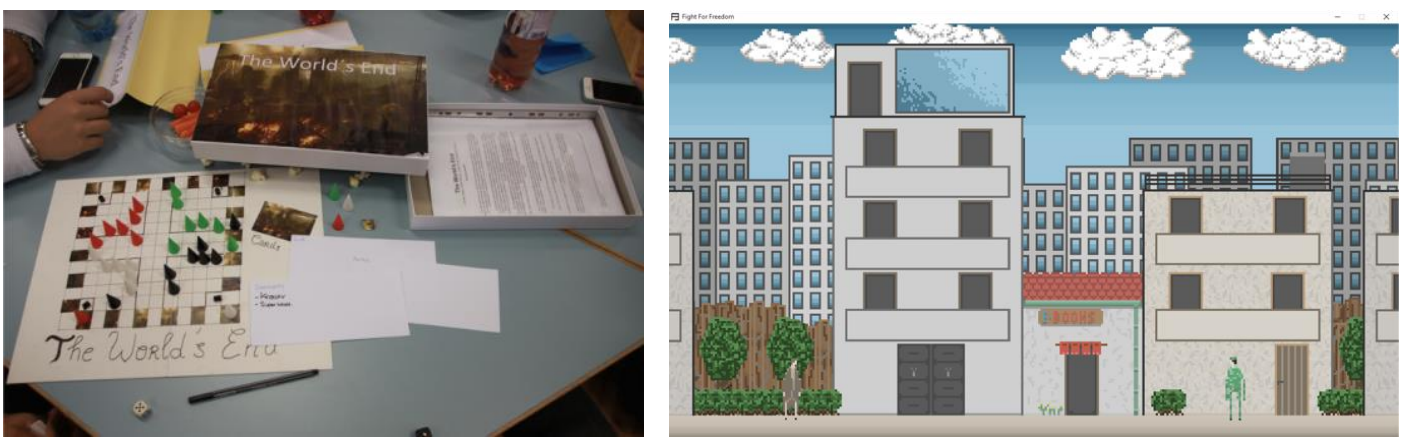

Figure 2. Student-created games from the Sparkling Games project. (a) The World's End is a tactical board game for two players, where they try to breach each other's firewall; (b) In the digital point and click adventure game Fight for Freedom players most work out how to orient themselves in a future society where analogue and printed media have ceased to exist.

The 11 board games mostly belonged to the genre categories of trivia (6 occurences) and objective race (6) games. Objective race games are board games, in which the player to first reach a finish line/goal on the board wins. Many games also contained elements of both the trivia and objective race genres. Other less popular genres included simulation (1), strategy (1) and word games (1). The most used game mechanics in the board games were roll/spin \& move (7), meaning to roll dice and move a piece accordingly, and linear movement (7) along a path on the game board. Other used mechanics include cooperative play (2) and dare or die (2), where players must perform a dare assigned either by other players or randomly to avoid loosing the round.

The 7 digital games are spread across different genres and contain elements of Jump'n'Run games (2), Role-playing Games (2), First-person Horror Games (1), Adventure games (1) and Beat'em up Games (1). The most used mechanics of the games include fighting (6), platforming (4), interactive narrative and dialogues (3), and loot and levelling (2).

Four of the 18 games did not make any significant connection to informatics and society topics despite students being prompted to do so. In the remaining 14 games the central themes were security (8), privacy (7), technological literacy (5), social media (4) and hacking (4). Other themes include surveillance (3), copyright (3), and cyber bullying (3). The game mechanics used most to convey those themes are competition (8), narrative (6) and prompting knowledge (6). Other mechanics include creative play (3), cooperation (2), letting players take a different perspective (2) and dystopian game worlds (2).

\subsection{Teacher evaluation}

The teacher evaluation was held as a two hour-long group discussion, where the four participating teachers critically reflected on the course of the project with four researchers of the project team. The main discussion points were:

- There was only little increase in the level of knowledge students had of topics from informatics and society. But there was a high degree of sensitisation for these topics they did not have previously, in particular towards data privacy, cryptography, password security, cyber mobbing and age-inappropriate content. This is of particular importance as those topics are not embedded in the students' regular curricula. These results are further confirmed by a pre- and post-test study with the participating students [24].

- We saw a clear increase in game design competency as a result of game design workshops and actively creating games. Showing the games at the GameCity fair was particularly motivating in that regard. For students who previously did not play a lot of games we also saw an increase in general game media literacy.

- There was a lot of social interaction among the students. The three schools had very different groups of students, and all were interested in interacting with students from the respective other schools. Also, students gave each other a lot of constructive feedback on the games they created. 
- We learned several lessons on how to better embed project-based teaching in schools; instead of spreading out sessions and workshops over a full year, it would be better to have more intense successive project days or a whole project week. It is hard to find incentives for students to work on their projects aside from scheduled session because they already have a very high workload. Teachers need more tools or indicators to judge progress of students during project-based work.

- The workshop and hands-on approach of the project was very well received by students. Talking to game design experts and academics helped motivate them. Students in particularly liked the larger gatherings where all three schools were present.

- To have sustained impact the resulting games and the applied game design methods need to be contextualised with the curricula of the involved school subjects (informatics and arts) and should be described as ready-to-use teaching modules, complete with instructions for preparation and reflection.

\section{Discussion}

Summarised, we successfully applied a project- and game-based approach to teaching informatics and society topics. While we couldn't show significant knowledge gains in this area, we overall measured an increase in awareness for topics from informatics and society and gains in game media literacy and game design competence. This is in line with the impact of learning games, which also raised awareness to cybersecurity issues [14,15]. The approach of hands-on workshops and creating games in a bottom-up process were well received by teachers and students alike, but a better embedding in the curricula and the schools' organisational structure was desired. This corresponds to the challenges identified by [10]. As evidenced by the presented project, project-based teaching in the classroom is preferable to traditional approaches when it comes to complex issues such as the ambivalent relation between technology and society. Independent student projects offer a combination of creative freedom, social learning and mutual feedback, and thus can also be appropriate for other challenging and interdisciplinary topics, e.g. diversity.

The most prominent topics identified in the database were more general and only loosely related to informatics and society; war, society and morality or moral decisions. The topic most identified that relates to informatics and society was hacking. In the created games the central themes were security, privacy, technological literacy, social media and also hacking. These areas correspond to the foci picked up by previous learning games in that space [1, 3, 5-11, 13-15]. Both in the examples discussed in the related work and in the students' games security is the most prominent area. The lack of informatics and society topics in the database is understandable - evaluation results showed that students had very little base knowledge and had to be sensitised for the existence and relevance of these topics.

The most popular genres in the database were open-world games and shooters, but none of the digital games fell into these genres (there jump'n'runs and role playing were the most prominent genres). The simple reason for this was that the open-world and shooter genres demand much more resources and time in development. [11]'s good learning results with action games might also relate to the genre preference towards shooter and open world games we saw. The most used mechanic in student-designed digital games was fighting. Board game genres were very simple with most using either trivia games and/or objective race games as the frame for their creations. Game mechanics that convey learning contents identified by students heavily focused on social interaction (competition, cooperation), and also included learning mechanics (acting strategically, change of perspective) similar to those described by J.P. Gee [2] and applied in our own previous work [3]. The importance of social interaction in both game-based and project-based learning was also confirmed in the group discussion with the teachers.

Overall none of the created games qualified as a dedicated learning game, instead the contents were embedded in more or less regular game concepts. Aside from trivia games the students partly struggled to meaningfully integrate the learning concepts into their games. Positive examples include games, in which the narrative of the game world educates players about informatics and society 
topics. The effort put into the games and subsequent quality of the student creations also varies greatly. About two thirds of the created games show that enough effort was put in. Especially in the digital games some of the students also overextended themselves on too broad scopes of their games. Following the three types of cybersecurity games outlined by [12], many of the board games fell into category 2, where contents were represented as multiple-choice trivia questions, but a lot of the other games succeeded in integrating the topics into the narrative and actual gameplay (type 3 ).

\subsection{Outlook}

Many approaches to using technology in learning are top-down. Technological solutions are applied in schools and their impact is tested with students. Our results stem directly from a bottomup approach with the target audience. They enable us to better orient the design of future learning games towards genres and concepts identified by students in games they like to play, and which they like to use when creating their own games. We could show that a project-based approach is suitable for integrating informatics and society topics into school teaching, but we also saw the need to first raise awareness for issues from that area. Future learning games can build on these insights by first sensitising players to issues and later incorporating more knowledge-oriented contents. We further learned that project-based teaching needs to be closely aligned with the curriculum and needs to accommodate requirements from daily practice in schools, such as good planning of resources and time, measures of success for teachers and clear instructions for preparatory and reflective work before and after such an intervention. Project-based teaching also provides a broad educational frame and opportunities beyond its primary purpose, as in our case we could also see increases in game design competence and game media literacy.

\section{References}

1. Valcke, M.; De Wever, B.; Van Keer, H.; Schellens, T. Long-term study of safe Internet use of young children. Computers \& Education 2011, 57(1), pp. 1292-1305.

2. Gee, J. P. What video games have to teach us about learning and literacy. Palgrave MacMillan: New York, 2007.

3. Kayali, F.; Wallner, G.; Kriglstein, S.; Bauer, G.; Martinek, D.; Hlavacs, H.; Rebbeca Wölfle. A Case Study of a Learning Game about the Internet. In Proceedings of the Serious Gamedays 2014, Darmstadt, Germany, April 1-4, 2014.

4. Nagarajan, A.; Allbeck, J.; Sood, A.; Janssen, T. Exploring game design for cyber-security training. In Proceedings of the IEEE Int. Conference on Cyber Technology in Automation, Control, and Intelligent Systems, Hong Kong, China. June 4-17, 2014, pp. 256-262.

5. Juhari, S. F.; Zin, N. A. M. No Educating Children about Internet Safety through Digital Game Based Learning. International Journal of Interactive Digital Media 2013, 1(1), pp. 65-70.

6. Wishart, J. M.; Oades, C. E.; Morris, M. Using online role play to teach internet safety awareness. Computers E Education 2007, 48(3), pp. 460-473.

7. Sheng, S., Magnien, B., Kumaraguru, P., Acquisti, A., Cranor, L. F., Hong, J., \& Nunge, E. Anti-phishing phil: the design and evaluation of a game that teaches people not to fall for phish. In Proceedings of the 3rd Symposium on Usable Privacy and Security, ACM: Pittsburgh, USA, July 18-20, 2007, pp. 88-99.

8. Kalaitzis, D.; Valeontis, E.; Delis, V.; Fountana, M. Experiences from Developing Online VR Environments: The "SimSafety" Case Study. Social Applications for Life Long Learning 2010, p. 8.

9. Xenos, M.; Papaloukas, S.; \& Kostaras, N.. The Evaluation of an Online Virtual Game Environment (SimSafety) using HOU's Software Quality Laboratory. Social Applications for Life Long Learning 2010, p. 63.

10. Irvine, C.E.; Thompson, M.F.; Allen, K. CyberCIEGE: gaming for information assurance. IEEE Security $\mathcal{E}$ Privacy 2005, 3(3). p. 61.

11. Heintz S; Law, E.L. Digital Educational Games: Methodologies for Evaluating the Impact of Game Type. ACM Transactions on Computer-Human Interaction (TOCHI) 2018, 25(2), p. 8.

12. Gestwicki, P.; Stumbaugh, K. Observations and opportunities in cybersecurity education game design. In Computer Games: AI, Animation, Mobile, Multimedia, Educational and Serious Games (CGAMES), IEEE: Louisville, USA, July 28-30, 2014. pp. 131-137. 
13. Gondree, M.; Peterson, Z.N. Valuing Security by Getting [d0x3d!] Experiences with a network security board game. Dudley Knox Library: Calhoun, Institutional Archive of the Naval Postgraduate School DSpace Repository, 2013.

14. Denning, T.; Lerner, A; Shostack, A., Kohno, T. Control-Alt-Hack: the design and evaluation of a card game for computer security awareness and education. In Proceedings of the 2013 ACM SIGSAC conference on Computer \& communications security. ACM: Nov 4, 2013, pp. 915-928.

15. Olano, M; Sherman, A.T.; Oliva, L.; Cox, R.; Firestone, D.; Kubik, O.; Patil, M.; Seymour, J.; Kohane, I.S.; Thomas, D. SecurityEmpire: Development and Evaluation of a Digital Game to Promote Cybersecurity Education. In Proceedings of the USENIX Summit on Gaming, Games and Gamification in Security Education (3GSE'14), USENIX: San Diego, USA, August 18, 2014.

16. Sparkling Games. Available online: http://www.piglab.org/sparklinggames (accessed on 26 July 2018).

17. Informatics curriculum. Available online: https://bildung.bmbwf.gv.at/schulen/unterricht/lp/lp_neu ahs_14 11866.pdf?61ebyw (accessed on 26 July 2018).

18. Braun V.; Clarke, V. Using thematic analysis in psychology. Qualitative research in psychology 2006, 3(2), pp.77-101.

19. Høbye, M.; Löwgren, J. Mediated Body: Designing for embodied experience, International Journal of Design 2014, 5(3), pp. 31-48.

20. Buxton, B. Sketching User Experiences: Getting the Design Right and the Right Design. Morgan Kaufmann, 2007.

21. Hallnäs, L.; Melin, L.; Redström, J. A design research program for textiles and computational technology. Nordic textile journal 2002, 1(2), pp. 56-63.

22. Aarseth, E. Playing Research: Methodological approaches to game analysis. In Proceedings of the Digital arts and Culture conference. MelbourneDAC: Melbourne, Australia, May 19-23, 2003, pp. 28-29.

23. BoardGameGeek. Available online: https://boardgamegeek.com (accessed on 26 July 2018).

24. Schwarz, V.; Kayali, F.; Götzenbrucker, G.; Purgathofer, P. Sparkling Games Student Evaluation Results (tentative title). Status: Manuscript in preparation. 